\title{
IMMIGRACIÓN Y POLÍTICAS DE PARTICIPACIÓN EN EL ÁREA METROPOLITANA DE VALÈNCIA
}

\author{
Andrea Kruithof Ausina \\ Licenciada en Ciencias Políticas y de la Administración por la Universitat de València ${ }^{1}$ \\ Contacto: andrea.kruithof@gmail.com
}

Fecha de recepción: 05/03/2016

Fecha de aceptación: 01/02/2017

\begin{abstract}
Resumen
El objetivo de este proyecto de investigación es identificar los mecanismos de participación disponibles para la comunidad de extranjeros asentada en la ciudad de València. Una breve introducción y descripción de los conceptos utilizados será seguida del análisis de la regulación local, principalmente los Planes de Integración valencianos, así como los organismos derivados de ella. La segunda fase presenta un análisis crítico de la situación, mostrando los puntos fuertes y débiles de las políticas de participación dirigidas a los inmigrantes. Este artículo intentará demostrar que el resultado de estas políticas no se corresponde con las intenciones de Planes, sugiriendo que no ha sido una prioridad para las autoridades públicas. Finalmente, se presentarán recomendaciones para el futuro, apostando por una mayor inclusión de los recién llegados en la vida pública
\end{abstract}

Palabras clave: Políticas públicas, integración, participación cívica y política

\section{INMIGRATION AND PARTICIPATION POLICIES IN THE METROPOLITANA AREA OF VALENCIA}

\section{Summary}

The purpose of this research paper is to identify the existing mechanisms of participation for the foreign community established in Valencia (Spain). A brief introduction and description of the main concepts used will be followed by the analysis of the local regulation, mainly Valencia's Integration Plans, as well as those organisms created by them. The second phase will present a critical analysis of the situation, showing the strengths and weaknesses of the policies that address the participation of immigrants. This article will try to prove that the outcome of these policies doesn't fit well with the intentions declared in the Plans, proving that it hasn't been a priority for the public authorities. Finally, some recommendations for the future will be presented, taking chance for a larger involvement of the newcomers in public life

\footnotetext{
${ }^{1}$ Este trabajo se ha realizado en el marco de los proyectos de investigación "Sostenibilidad y competitividad urbanas en un contexto global. El área metropolitana de Valencia (CSO2013-46863-C3-1-R) y Estructura social, encuestas y elecciones (CSO2013-43054-R) financiados por la convocatoria 2013-Proyectos I+D+IPrograma estatal de Investigación, Desarrollo e Innovación orientada a los retos de la Sociedad del Ministerio de Economía y Competitividad.
} 
Key words: Public politics, integration, civic and political participation

\section{INMIGRATION ET POLITIQUES DE PARTICIPACION DANS LA RÉGION MÉTROPOLITAINE DE VALENCE}

L'objectif de ce travail est d'identifier les mécanismes de participation disponibles pour les communautés étrangères qui vivent à Valence (Espagne). Notre brève introduction et description des concepts utilisés sera suivie d'une analyse critique de la réglementation, principalement des Plans d'Intégration valenciens, en même temps que ceux des organismes qu'ils ont eux-mêmes créés. La deuxième phase présentera une analyse critique de la situation, tout en montrant les points forts et les faiblesses des politiques de participation envers les immigrants. Ce papier essaie de démontrer que le résultat de ces politiques ne correspond pas aux intentions des Plans, problématique qui suggère qu'elles n'ont pas constitué une priorité pour les pouvoirs publics. Finalement, nous présenterons des recommandations pour l'avenir, tout en misant sur une plus grande inclusion des nouveaux arrivants.

Mots-clés: Politiques publiques, integration, participation civique et politique

"Butterflies have always had wings; people have always had legs", Harsha Walia

\section{INTRODUCCIÓN}

La historia de las migraciones es la historia de la humanidad. No obstante, nunca como ahora tanta gente se había encontrado en movimiento; se calcula que 232 millones de personas buscan en otros países diferentes al suyo nuevas oportunidades -alrededor del $3 \%$ de la población mundial-. En nuestro entorno, la ciudad de Valencia, la población extranjera empadronada se ha multiplicado por 11 en 9 años, pasando de representar el $1.6 \%$ del total de la población el año 2000 , al $15.1 \%$ en 2009 . La crisis ha tenido como consecuencia un ligero descenso de este porcentaje, que no justifica la creencia de que se ha producido una salida 'masiva' de inmigrantes, ni siguiera un retorno significativo a los países de origen. En todo caso podríamos hablar de una frenada en la entrada, pero tenemos alrededor nuestro una heterogeneidad social que ha venido para quedarse. $Y$ eso implica el replanteamiento político de la organización de nuestra sociedad.

Hasta la actualidad, gran parte de la literatura ha abordado la inmigración desde un enfoque estrictamente laboral o administrativo, cimentado en los flujos migratorios dirigidos a suplir la demanda de mano de obra. El debate se viene centrando, por norma general, en un marco economicista: para unos, en la (in)capacidad del mercado para absorber una ingente masa de trabajadores extranjeros $-y$, en consecuencia, la necesidad de regular las entradas y salidas en función del estadio del ciclo económico-; para otros, sus efectos positivos, también en términos monetarios. En mucha menor medida se consideran sus derechos básicos, o su contribución a enriquecer y dar nuevas perspectivas 
a nuestra sociedad. En otras palabras, no es frecuente encontrar textos que analicen el capital social de la inmigración.

A pesar de ello, nos encontramos en un cambio de paradigma. Hasta hace poco los migrantes asentados en Europa -u otros contextos similares de acogida- eran vistos como meros objetos de estudio o como receptores pasivos de las políticas públicas, sin abandonar esta vinculación migración-trabajo que ha caracterizado las políticas migratorias en todo el mundo. Progresivamente, se difumina esta visión del Gestarbeiter, para dar paso a un migrante vinculado al concepto de ciudadanía, el vecino foráneo planteado como posible actor político. A medida que comienza a visibilizarse la falta de recursos políticos de este sector de la población, el problema se convierte en problema público, es decir, se reconoce en las instituciones que se trata de una situación conflictiva, y entonces se incluye en la agenda de actuación de gobierno. Toda política pública apunta a la resolución de un problema público, como nos dice Subirats $(2014 ; 45)$, o en otras palabras, se trata de una respuesta institucional a una situación entendida como inadmisible. Así pues, cuando en la presente investigación analizamos la participación y la integración a la área de Valencia, lo enfocamos a partir de las políticas públicas; es decir, cual es la respuesta politicoadministrativa- en este caso del gobierno local- a una situación que de manera consciente se entiende como problemática.

Es evidente que los conceptos de inmigración e integración no están exentos de conflicto. Así lo denota el ascenso de fuerzas políticas que exigen controles de fronteras más estrictas, y/o el tratamiento mediático de las diferencias culturales y religiosas ${ }^{2}$.

$\mathrm{Si}$ en algo coinciden las múltiples posiciones es en hacer de este tema - la inmigración y sus efectos en el entorno - el centro de su debate. Cuando hablamos de temas relacionados con las migraciones, por tanto, es inevitable incluir el concepto de integración (aunque fuera para negar su existencia). Se habla 'de identidades reactivas' (Monsiváis Carrillo, 2002), de incompatibilidades culturales -en lógica argumentativa con el famoso 'choque de civilizaciones' de Huntington-, o bien de multiculturalidad o interculturalidad, del 'melting pot americano'...

Son múltiples las perspectivas desde las que aproximarse a la inmigración. El rol que los migrantes juegan en la vida política de su nuevo espacio de residencia, es, a ojos de muchas instituciones -entre las cuales destacamos la Unión Europea-, una dimensión más de esta integración a pesar de las reservas de algunos Estados, ya que la participación representa una parte integral de la vida de las personas ${ }^{3}$. Pocos son los que no reconocen que la ciudadanía y la integración de los nuevos ciudadanos se han convertido en cuestiones claves sobre las políticas públicas europeas. La sociedad valenciana tampoco vive ajena a este debate. Inmersa en un intenso proceso de transformación social, la

\footnotetext{
${ }^{2}$ La portada del diario 'El Mundo' de septiembre de 2014, se expresaba, por ejemplo de la siguiente manera, "El Estado Islámico sueña con conquistar Al Andalus". Como nos dice Santiago Alba Rico en su artículo para Rebelión.org, "alimenta entre los lectores la ilusión de una amenaza inminente y justifica por anticipado las medidas que se tomen, a escala nacional e internacional por defender nuestro territorio" Portada del diario en la web: <http://www.elmundo.es/internacional/2014/09/03/540768e0ca4741406e8b456b.html>

3 Coussay, M., y Sem Christensen, E. (Chairman), 1997, Measurement and indicators of integration, Community Relations, Directorate of Social and Economic Affairs, Council of Europe Publishing
} 
diversidad podría convertirse en un motor de cambio social. Nos proponemos analizar, por lo tanto, qué papel juega la integración política de los inmigrantes en la política local.

En este trabajo no se plantea una postura neutral al respecto. Más bien al contrario, entendemos que la integración es el mejor de los escenarios posibles, y que la participación social y política de las personas migradas es una de las claves -o debe constituirse como tal- en el proceso de integración. Tampoco cuestionaremos, en consecuencia, la presencia de población de origen extranjero en nuestro territorio, situación entendida como inevitable. Como ya hemos dicho anteriormente, el impacto de la crisis en los flujos migratorios no ha sido suficientemente importante para hacer menguar la ya estabilizada heterogeneidad social ${ }^{4}$. Este nuevo escenario supone un desafío para el sistema de representación español, en la medida que buena parte de la ciudadanía es invisibilizada en los procesos de toma de decisión.

El cambio profundo en el origen y composición de nuestra sociedad, imprevisible en los inicios democráticos, presenta implicaciones múltiples, $y$, principalmente, una pregunta: ¿Cómo encaja la población inmigrante -que a estas alturas supone un nada menospreciable $13.1 \%$ del conjunto en nuestra ciudad- en nuestras instituciones? Hacemos hincapié en la representación y la participación política, ya que entendemos que sin sentimiento y consciencia de identidad, de pertenencia y de protagonismo en las políticas públicas, resulta muy difícil hablar de integración social ${ }^{5}$.

Este dilema se suma a toda una serie de cuestiones que ponen en duda la capacidad de los gobiernos para rendir cuentas y ser receptivos a las demandas ciudadanas. El Comité de Ministros del Consejo de Europa ya identificaba en $2001^{6}$ tres problemáticas relacionadas con nuestro sistema democrático:

1. El declive del interés del público y un tedio respecto a la política

2. La dificultad de implicar más al público mediante formas directas o populares de consulta y participación

3. Las debilidades de las instituciones de la democracia representativa local, que hacen el sistema menos eficaz, transparente y responsable

No es casual en absoluto la frecuencia con la que se usa la expresión 'renovación democrática' en la actualidad política, como tampoco lo es la de otros términos análogos como 'participación ciudadana'. La cuestión es como encajan los nuevos ciudadanos en esta perspectiva de cambio.

A la vista de lo que se ha expuesto hasta el momento, el presente trabajo pretende hacer un análisis de los diferentes planes del Ayuntamiento de València, con tal de observar si sus políticas públicas se adecuan a los nuevos tiempos. Para ser más específicos, nos centramos en las personas que se encuentran en situación de regularidad administrativa. Analizaremos, así pues, diferentes definiciones que no sitúen en contexto, para pasar después a perfilar con más detalle el marco normativo -la legislación vigente y

\footnotetext{
${ }^{4}$ Con todo, cabe puntualizar que la heterogeneidad social no aparece con la inmigración, sino que es propia de cualquier sociedad.

${ }^{5}$ Al respecto, ver de Lucas Martín, J., Añón Roig, M.J., et al, 2008, Los derechos de participación como elemento de integración de los inmigrantes, Informes 2008, Economía y Sociedad, Bilbao: Rubes Editorial, Fundacion BBVA

${ }^{6}$ Recomendaciones del Comité de Ministros del Consejo de Europa, 6 de diciembre de 2001
} 
los Planes de Integración en cuestión. Finalmente, se presentarán las conclusiones, en las cuales se evaluará su adecuación al nuevo contexto; y, por último, se darán algunas recomendaciones de como debería mejorar-se la situación, pensadas para el caso concreto de la ciudad de València, aunque podrían aplicarse a otros contextos similares.

\section{DEFINICIONES. INTEGRACIÓN, EXCLUSIÓN SOCIAL Y PARTICIPACIÓN}

Las políticas públicas, hemos dicho, tienen como objetivo primero solucionar aquello que las instituciones entienden como un problema. Pero no se trata únicamente de definir la orientación de las políticas aplicables; la constitución y definición de problemas públicos también forma parte del proceso, e influirá, determinará incluso, los actores involucrados, así como la naturaleza de las acciones públicas. En nuestro caso, de cómo definamos 'integración', 'participación' y 'exclusión social', dependerá tanto el contenido y los instrumentos de gestión pública, como las formas de gobernanza que se acaben adoptando.

\subsection{La integración}

Nuestro análisis se centra en la visión más dinámica de la integración; no tanto en las relaciones estables y cooperativas en un sistema social definido, como en el seguimiento del proceso que las rodea, el fortalecimiento -o deterioro- de estas mismas relaciones cuando se introducen actores y grupos nuevos dentro del sistema y sus instituciones. Desafiando las perspectivas convencionales o economicistas del desarrollo, que tienden a entender la integración social como 'la uniformidad de las relaciones sociales ${ }^{17}$, buscamos un concepto con vocación de pluralidad, que sea respetuoso con la diversidad. Y que, además, implique a todos los ámbitos del ser humano, incluyendo el político. Así se entiende también en el marco europeo ${ }^{8}: " L a$ integración implica el respeto de los valores básicos de la UE. La participación de los inmigrantes en el proceso democrático y en la formulación de las políticas y medidas de integración, especialmente a escala local, favorece su integración". En ese sentido, cuando aquí hablamos de integración lo hacemos de manera que podría ser intercambiable con el término inclusión.

Cuando hablamos de la integración generalmente pensamos en el acceso al mercado de trabajo y a los servicios (educación, sanidad, vivienda...) en igualdad de condiciones que los locales. Es también donde se han centrado la mayoría de esfuerzos públicos. Y aunque es vital atender esta inequidad, no podemos descuidar el papel político. La integración que aquí nos interesa tiene nombres y apellidos: integración cívica o política, su vertiente más descuidada.

\footnotetext{
${ }^{7}$ En el sentido de plantear políticas y programas de desarrollo de carácter homogeneizador. En estos modelos convencionales de desarrollo la cultura y la tradición representan obstáculos a superar para conseguir la integración.

8 EUR-LEX, 2 diciembre 2010, Marco común para la integración de nacionales de terceros países, http://europa.eu/legislation_summaries/justice_freedom_security/free_movement_of_persons_asylum_im migration/l14502_es.htm
} 


\subsection{La exclusión social.}

La integración cívica de las personas migradas, tal como se ha planteado en el apartado anterior, se nutre de un concepto de ciudadanía plural e inclusiva, capaz de hacer partícipes de los beneficios de formar parte de una comunidad a los recién llegados, es decir, capaz de convertirlos en ciudadanos de pleno derecho ${ }^{9}$. La falta de integración nos remite al siguiente concepto que consideramos indispensable argumentar: el de exclusión social. Este concepto se ha asumido como el que mejor explica las situaciones de desigualdad y vulnerabilidad múltiple características de nuestro entorno ${ }^{10}$. Incluye la pobreza pero no se limita a ella; también se define por la imposibilidad o dificultad grave de acceder a los mecanismos de desarrollo personal y de inserción sociocomunitaria y a los sistemas preestablecidos de protección. La exclusión social es, por lo tanto, 'el proceso que relega algunas personas al margen de la sociedad y que les impide participar plenamente a causa de su pobreza, a la falta de competencias básicas y oportunidades de aprendizaje permanente, o por motivos de discriminación. Esto las aleja de las oportunidades de ocupación, percepción de ingresos y educación, así como de las redes y actividades de las comunidades. Tienen poco acceso a los organismos de poder y decisión $y$, por eso, se sienten indefensos e incapaces de asumir el control de las decisiones que les afectan en su vida cotidiana ${ }^{11 "}$.

Este es un fenómeno multicausal, poliédrico, del que se derivan un cúmulo de circunstancias desfavorables, entrelazadas y muy difícilmente individualizables. La exclusión difícilmente admite definiciones segmentadas ${ }^{12}$. Es importante entender, como nos recuerda Subirats (2008;1), que "la propia situación de exclusión, y la multiplicidad de factores que la generan, dificultan que surja del si de esas personas y colectivos la fuerza necesaria para generar un sujeto homogéneo y articulado de cambio histórico, visible y con capacidad de superación de la exclusión. De aquí que sea mucho más complicado generar procesos de movilización y definir una praxis superadora de la exclusión". Por eso mismo la invisibilización política debe constar entre una de las ramificaciones de la exclusión social, y la lucha por superarla ha de incluir mecanismos contra la falta de incidencia política en la esfera pública.

\footnotetext{
9 de Lucas Martín, J., Añón Roig, M.J., et al, 2008, Los derechos de participación como elemento de integración de los inmigrantes, Informes 2008, Economía y Sociedad, Bilbao: Rubes Editorial, Fundacion BBVA, pàg. 41

${ }^{10}$ Bifarello, M., Subirats, J., et al., , Reflexiones en torno a la implementación de Políticas Públicas Locales que buscan la Cohesión Social, Barcelona: Oficina de Coordinación y Orientación (OCO), Programa URB-AL II, pág. 50

11 Sierra Fonseca, R., 29 Febrer, Integración social y equidad en la perspectiva del desarrollo humano sostenible, 1‥ed. -Tegucigalpa: PNUD,

${ }^{12}$ Bifarello, M., Subirats, J., et al., , Reflexiones en torno a la implementación de Políticas Públicas Locales que buscan la Cohesión Social, Barcelona: Oficina de Coordinación y Orientación (OCO), Programa URB-AL III
} 


\subsection{La participación cívica y el capital social}

Por último, cabe insistir en la idea de participación. Este término invita al debate, no solamente por su transcendencia, sino por la grandísima variedad de definiciones con la que es posible encontrarse. Aquí nos fijamos en la acepción de Font, Montero y Torcal (2006: 30), puesto que valoran la participación desde una perspectiva más amplia a la que estamos acostumbrados. Desde su óptica son "los actos o actividades realizadas por cualquier ciudadano que tratan de influir directamente o indirectamente en las decisiones adoptadas por las autoridades políticas y sociales (elegidas o no) y que afectan a los asuntos de la colectividad"13. La participación, por tanto, transciende las formas convencionales vinculadas al derecho al voto.

La participación es un proceso relacional, que vincula los sujetos y los grupos, que conecta todas las personas involucradas en los procesos que les afectan. Es una experiencia comuna, con capacidad para generar una conciencia compartida. Como nos dice Mora (2014; 5), "ser participante implica ser coagente, cooperante, coautor, corresponsable..." en aquellas actividades que tienen como objetivo influir, de manera directa o indirecta, en la agenda pública. En ese sentido, el no reconocimiento de la condición juridicopolítica de la ciudadanía no implica estar excluido totalmente del espacio público. De hecho, son muchas las personas que intervienen en la sociedad e inciden en ella a través de otros mecanismos de ciudadanía social o cívica, definida como el "campo de derechos, responsabilidades y prácticas, pertenencias y sentimientos que se expresan primordialmente en las ciudades y pueblos, en las comunidades vecinales y de barrio, en la sociedad civil en su conjunto" (Mora, 2014; 5).

Hasta el momento, los instrumentos de participación alternativos al sufragio se han articulado alrededor de tres ejes fundamentales: la participación en asociaciones de inmigrantes, la participación en órganos consultivos y la participación en procesos consultivos públicos. Algunos autores, como Putnam (1993), ha remarcado que el buen funcionamiento de la democracia está relacionado con la participación cívica de los ciudadanos, concretamente a través de las asociaciones, que evalúa positivamente por ser espacios de construcción de proyectos colectivos. Según él, la organización en entidades es una clara manifestación de ciudadanía, especialmente relevante en contextos como el que aquí comentamos, de no acceso al conjunto de los derechos de participación. Las asociaciones tienen la capacidad de compensar, a través de discursos y prácticas alternativas, la falta de poder a la que se enfrentan determinados colectivos. Dicho de otra forma, el asociacionismo puede ser una herramienta en la creación de 'capital social', entendido como "el agregado de recursos reales o potenciales ligados a la posesión de una red duradora de relaciones más o menos institucionalizadas de reconocimiento mutuo" (Bourdieu, 1986: 248).

Con tal de evaluar el efecto de las asociaciones de inmigrantes, debemos ser conscientes de su capital social, que se puede subdividir en tres categorías:

\footnotetext{
${ }^{13}$ Visto en Mora, A: La participación social y política como instrumento de integración, módulo 4, Máster en migraciones y ciudadanía, Universitat de València.
} 
A Capital social de vínculo -o la representatividad-, es el conjunto de relaciones tejidas entre el asociacionismo y el colectivo inmigrante al que pretende dar voz. Este capital social legitima la existencia de la entidad, interna y externamente. Los vínculos que enlazan a las personas foráneas con sus asociaciones y sobre las que se construye este capital social de vínculo son heterogéneas y dinámicas. Pueden tener un componente de identificación que responda a patrones étnicos, cuando se tiene la necesidad de buscar a quien vemos como un igual. Se puede tener, por otra parte, un vínculo de necesidad con aquellas ONG proinmigrantes dirigidas a satisfacer las necesidades básicas. En esta variedad, no obstante, el vínculo durará tanto tiempo como se sea beneficiario de la atención -o se necesite un servicio determinado-. En la Comunitat Valenciana $y$, por extensión, en València, predomina este segundo tipo, que se caracteriza por una limitada y frágil vinculación ciudadana.

A Capital social de puente, que hace referencia a las relaciones creadas dentro del tejido organizativo, ya sea otras con ONG o AMPA, asociaciones de vecinos, etc. Existen diferentes grados de relación: desde el intercambio de información -el nivel más bajo- hasta las plataformas estables en red, pasando por toda una serie de escalones intermedios. A pesar de que en la Comunitat Valenciana ha existido el interés por crear este tipo de federación, en general han sido iniciativas sin un largo recorrido (Mora, 2010; 13).

A Capital social de acceso. Este último tipo engloba la participación de las entidades en el diseño y ejecución de las políticas públicas en sus diversos niveles. El asociacionismo inmigrante en València, ha desarrollado un limitado capital de acceso, por la combinación de factores internos -falta de conocimientos, desinterés, entre otros- y externos -espacios de participación limitados, falta de poder de decisión real, etc.-.

\section{MECANISMOS DE PARTICIPACIÓN (EL ENFOQUE INSTITUCIONAL)}

\subsection{Marco normativo}

Cabe entender, en primer lugar, que en términos de participación el Ayuntamiento de València, al igual que otros ayuntamientos, tiene 'las manos atadas'. Es decir, hay posibilidades restringidas, que se derivan de las directrices constitucionales, estatales y autonómicas. La más importante de las delimitaciones con la que nos encontramos viene marcada por la Constitución Española. En su artículo 13.2 se establece que "Solamente los españoles serán titulares de los derechos reconocidos en el artículo 23, salvo lo que, atendiendo a criterios de reciprocidad, pueda establecerse por tratado o ley para el derecho de sufragio activo y pasivo en las elecciones municipales". El artículo 23, por su parte, hace referencia al derecho a participar en los asuntos públicos como electores y como elegibles. Como señala Moya $(2010 ; 463)$, la Constitución establece dos niveles distintos de participación política representativa en España. Tenemos un nivel más bajo, donde se incluye el sufragio municipal, en el que se permite concurrir a los inmigrantes 
siempre que se de el criterio de reciprocidad -es decir, que los españoles también puedan votar en el país de origen de estos-. Y, por otro lado, un nivel políticorepresentativo superior, el de las elecciones autonómicas y estatales, al que les está vetado el acceso. La posterior interpretación judicial ${ }^{14}$ de estos dos artículos no deja lugar a dudas: el derecho del sufragio se restringe a los comicios locales, aunque para poder justificarlo tenga que considerar -de forma más que cuestionable- que se trata de elecciones administrativas.

La exigencia de reciprocidad también crea categorías dentro del colectivo de extranjeros a la hora de ejercer su derecho electoral. Pese a los esfuerzos gubernamentales para ampliar el círculo de países con los que se acuerda el derecho a participar en las elecciones, siempre habrá un apartado de 'damnificados', ya sea por la falta de acuerdo institucional o bien por la inexistencia de sistemas de gobierno equiparables al del Estado español - por ejemplo, en el caso de que no existan elecciones a nivel local o que no sean libres y democráticas ${ }^{15}$. Podemos imaginarnos una escala de permisividad organizada en 5 categorías, como se ilustra en el siguiente gráfico:

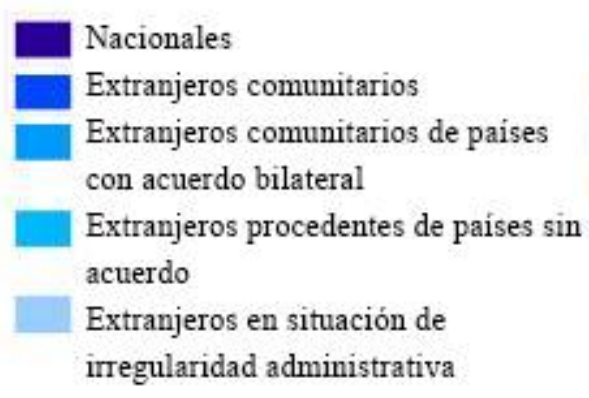

Nacionales

Extranjeros comunitarios

Extranjeros comunitarios de paises con acuerdo bilateral

Extranjeros procedentes de paises sin cuerdo irregularidad administrativa

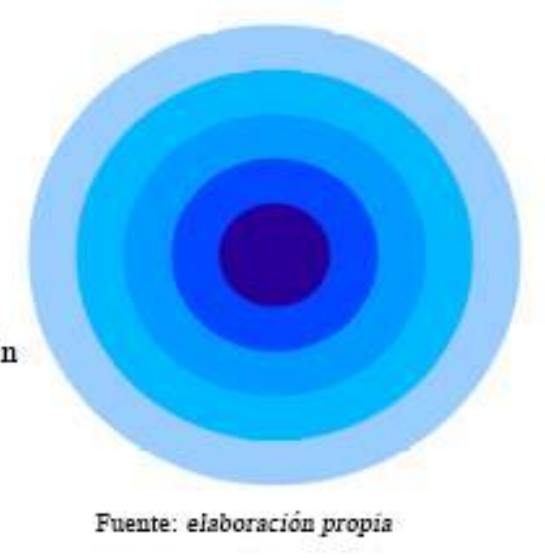

A medida que nos alejamos del núcleo, los derechos participativos se diluyen, hasta llegar a la situación de total desamparo de las personas en situación administrativa irregular.

Se trata, además, de una cuestión de competencias. El gobierno central se reserva las competencias de Extranjería (artículo 149.1.2 de la Constitución). La Ley Orgánica de Extranjería (de ahora en adelante LOEx), es la encargada de regular los derechos políticos de los extranjeros, entre los cuales nos interesa especialmente mencionar los derechos de participación pública, y los derechos de reunión, manifestación y asociación. La participación pública de este colectivo remite a lo dispuesto por la Constitución (recordemos lo comentado respecto al derecho a sufragio en las elecciones locales). Por su parte, el segundo grupo de derechos está regulado de manera muy restrictiva por la la LOEx, cosa que llevó a considerar inconstitucional esta primera redacción del texto. En él, se condicionaba el reconocimiento de los citados derechos a la situación jurídica de los

\footnotetext{
${ }^{14}$ Declaración 1/1991 del Tribunal Constitucional sobre el alcance e interpretación del artículo 13.2 CE

${ }^{15}$ Para un análisis más detallado sobre el derecho de sufragio de los extranjeros extracomunitarios se recomienda la consulta de Moya, D.
} 
beneficiarios. El Tribunal Constitucional entendía, asimismo, que este requisito violaba unos derechos inherentes a la dignidad humana, por lo que se necesitó una nueva reforma. En la actualidad, la ley establece que "los extranjeros disfrutan de estos derechos en las mismas condiciones que los españoles" (artículos 7 y 8), con lo que termina la subordinación a la autorización de estancia o residencia para tenerlos garantizados.

Por lo que respecta a las competencias específicas de las administraciones locales, desde la aprobación de la LOEx 4/2000, se ha insistido en el papel nuclear de los poderes locales en relación a los derechos y deberes de los extranjeros (Lucas Martín et al, 2008; 99), ello incluye algunas posibilidades de participación política, la gestión de servicios a los que éstos pueden acceder, y la adquisición de la condición de vecindad a través del padrón municipal. La participación parte del artículo $6.3 \operatorname{LODYLE}^{16}$, que reconoce a los extranjeros residentes y empadronados en un municipio todos los derechos que les corresponden como vecinos, añadiendo además que podrán ser escuchados en los asuntos que les afectan, de acuerdo con aquello dispuesto en los reglamentos de aplicación. Esta última posibilidad, como nos indica Moya, tiene únicamente una intención reiterativa, puesto que les corresponde por el simple hecho de ser vecinos empadronados (Moya, 2010; 494)-. Más allá, los procedimientos de participación ciudadana establecidos en la legislación del régimen local de cada municipio permiten a los ayuntamientos, en uso de su autonomía local, establecer aquellos mecanismos y procedimientos de participación que consideren adecuados, con el único límite de la legislación general y la previsión del artículo 69 LRBRL $^{17}$ de no perjudicar la capacidad decisoria de los órganos representativos del municipio (Moya, 2010; 494).

\subsection{Los Planes de Integración.}

Como viene siendo frecuente en la gestión local de la inmigración en el conjunto del estado, el Ayuntamiento de València también cuenta con Planes Municipales de Inmigración, que enumeran los instrumentos específicos de los que se dota el consistorio. Estos ordenan el conjunto de actuaciones, establecen las responsabilidades de las diferentes áreas municipales, el papel de las organizaciones sociales, etc.

En este apartado se han analizado los Planes actualmente en vigor y que afectan a nuestro objeto de estudio: el II Plan de Inclusión Social 2014-2017, aprobado el 25 de abril de 2015; y el Plan Norte-Sur 2009-2013, prorrogado a falta de la aprobación de un nuevo Plan que lo substituya. También se han incluido los textos que precedieron a la actual normativa, a saber, el I Plan Municipal para la Integración de la Inmigración (2002-2005), así como el Plan Municipal de Servicios Sociales para la Inclusión Social 2006-2010, que, aunque no se centre exclusivamente en el tema que aquí se trata, incluye el colectivo de inmigrantes entre los grupos en riesgo de exclusión social.

Poco a poco, la participación política de los ciudadanos extranjeros ha ido cobrando importancia. En este sentido, en el I Plan Municipal para la Integración de la

\footnotetext{
${ }^{16}$ Ley Orgánica 8/2000, de 22 de diciembre, de reforma de la Ley Orgánica 4/2000, de 11 de enero, sobre derechos y libertades de los extranjeros en España y su integración social.

${ }^{17}$ Ley 7/1985, de 2 de abril, reguladora de las Bases del Régimen Local Vigente hasta el 02 de Octubre de 2016).
} 
Inmigración (2002) ya se mostraba un interés en la inclusión política del colectivo, puesto que constaba entre los objetivos que se proponía conseguir: "[El Plan] tendrá como finalidad genérica el diseño y desarrollo de una política municipal dirigida a la integración de las personas inmigrantes en la vida política, económica, cultural y social de la Ciudad de

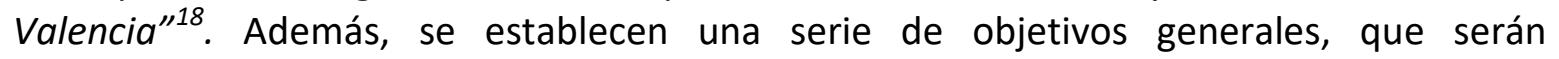
continuados por los Planes actuales. En concreto, se citan los siguientes:

A Equiparar derechos y deberes de todas las personas y garantizar el principio de igualdad de oportunidades en todos los ámbitos de la vida social valenciana

4 Desarrollar acciones positivas, adaptando medidas específicas dirigidas a combatir las discriminaciones que sufren las personas inmigrantes en el ejercicio de sus derechos y en el acceso a los bienes y servicios existentes

A Garantizar los principios de responsabilidad pública y de participación del tercer sector en la gestión de las políticas social de inmigración

A Propiciar vías de participación y diálogo que permitan canalizar las demandas y necesidades del colectivo de inmigrantes

En estos objetivos vemos algunas de las cuestiones claves que seguirán desarrollándose con los años, principalmente la voluntad de equiparar los derechos de participación de los inmigrantes en la medida de lo posible.

En el II Plan de Servicios Sociales para la Inclusión Social las referencias a la participación son aún más frecuentes, especialmente con lo que respecta a la 'declaración de intenciones ${ }^{19}$. Por coherencia se entiende que el principio participativo debe tenerse en cuenta en la elaboración misma el $\operatorname{Plan}^{20}$, que incluye también su seguimiento y evaluación (los informes de seguimiento anual, así como la evaluación final), que le corresponderá al Consejo de Acción Social. Este, una vez informado, podrá hacer las propuestas pertinentes.

Hasta aquí, poca novedad respecto del primer Plan de Integración. Puede que lo que lo aleja más es una elaboración más intensa del papel del asociacionismo inmigrante en la integración cívica del colectivo que, como veremos, se convierte en el eje vertebrador de las políticas públicas de participación. En este sentido, se pretendía validar la propuesta incluyendo diferentes asociaciones que aportaran sus propuestas de mejora o modificación del presente Plan. En concreto se llevaron a cabo 5 jornadas de validación entre septiembre y octubre de 2013, una por cada sector (Mayores, Discapacidad, Mujeres, Familia y Menores, Inmigración y Exclusión Social), en las que se implicaron,

\footnotetext{
${ }^{18}$ I Plan Municipal para la Integración de la Inmigración, pág. 12.

19 “ (...) En una administración pública moderna y próxima a la realidad social, debemos contar con todas las personas y todos los agentes implicados en la acción social. Personas como protagonistas de la intervención que se desea realizar y agentes como sujetos de la acción. Este planteamiento supone formar parte de la planificación de las políticas sociales en todas sus fases", II Plan de Servicios Sociales para la Inclusión Social 2014-2017, Ayuntamiento de València, Concejalía de Bienestar Social y Integración, pág. 26

20 II Plan de Servicios Sociales para la Inclusión Social 2014-2017, Ayuntamiento de València, Concejalía de Bienestar Social y Integración, pág. 25
} 
además del equipo de técnicos y personal de la administración pública valenciana, un total de 64 organizaciones del Segundo y Tercer Sector ${ }^{21}$.

Eso nos da ya algunas pistas de como se articularán las diferentes propuestas de participación. Las restricciones legales han potenciado que el gobierno local de nuestra ciudad se haya centrado en vías alternativas de participación, concretamente en mecanismos de lo que se ha definido como participación social o asociativa. Las asociaciones destacan por su papel preponderante en la negociación política (objetivos 3 y 5). También se hace referencia a la necesidad de investigar más a fondo sobre cuestiones -entre las que se incluye el asociacionismo- que impliquen a la inmigración, con tal de prevenir la exclusión social de este colectivo (El objetivo 3.2.3). Pero lo más importante se deriva del objetivo 5 , que tiene como meta principal la inclusión del tercer sector: "Involucrar a la totalidad de agentes sociales con la implicación en el ámbito de la inclusión social".

Las diferentes actuaciones dirigidas al colectivo aquí estudiado se vehiculan a través de diferentes entidades y/o organismos. El Plan dispone los recursos con los que se cuenta:

- Centro de Atención al Inmigrante (CAI). - Información/Asesoramiento.

- Mesas de Solidaridad

- Consejo Municipal de Acción Social del Ayuntamiento de València.

- Comisión de Inmigración

- Impulso de proyectos en red

El Plan Norte-Sur, por su parte, también hace múltiples referencias a la implicación de las personas migradas en la planificación y programación de las políticas públicas ${ }^{22}$, a la equiparación de derechos, y a la corresponsabilidad de los agentes sociales ${ }^{23}$ entre los principios que deberán guiar las diferentes acciones propuestas. El Plan Norte-Sur añade, además, la necesidad de 'propiciar vías de participación y diálogo con tal de canalizar las demandas y necesidades del colectivo'. De nuevo nos encontramos con que la participación se vehicula principalmente a través de las asociaciones.

El plan se estructura en tres programas -Inmigración, Cooperación al desarrollo y Codesarrollo-, que constan de tres dispositivos transversales: La Oficina Técnica, el Observatorio Norte-Sur y Valencia Espacio Abierto. Como parece lógico, en el presente trabajo nos centramos en el primer apartado -Inmigración-, que se divide en 7 áreas: Primera acogida, Información, Orientación y asesoramiento, Educación, Interculturalidad, Salud, Trabajo y, finalmente, Participación y Asociacionismo. Dentro de estas áreas destacamos que la participación es un elemento con vocación de transversalidad (a excepción tal vez, del área de Salud y de Trabajo, donde se prioriza garantizar el acceso en igualdad de condiciones), con lo que se incluyen varias herramientas en otros ámbitos que

\footnotetext{
${ }^{21}$ Organizaciones privadas, diferenciadas del sector público, con intención lucrativa -Segundo sector- y sin Tercer sector-.

22 Plan Norte-Sur 2009-2013, Junio 2008, Sección de Estudios y Planificación, Sección de Participación Social, Concejalía de Bienestar Social e Integración, Ayuntamiento de València, pág.12 ${ }^{23}$ idem
} 
no son el de Participación y Asociacionismo. Así pues, el área de Información, Orientación y Asesoramiento tiene como objetivo informar de los derechos y de las obligaciones, recursos y servicios. Destacan las siguientes medidas:

- Información y acompañamiento en procesos de tipo administrativo para la regulación, reagrupamiento, retorno...

- Información y recomendación del empadronamiento de la población inmigrante (elemento indispensable para poder votar/ser elegido en los comicios locales).

Por lo que respecta al área de Educación, nos encontramos como medida propuesta el 'fomento de la participación de los padres y madres en AMPA (Asociaciones de padres y madres de alumnos)'. En el apartado de Interculturalidad, destacan las finalidades de:

- Fortalecer la capacidad organizativa y participativa de las asociaciones de inmigrantes', así como de

- Favorecer la integración de inmigrantes en asociaciones culturales, recreativas o otras de la ciudad,es decir, en asociaciones que no sean específicamente de inmigrantes ni de apoyo a la inmigración.

Mientras que en los apartados de Información, Orientación y Asesoramiento, Educación e incluso Interculturalidad nos encontramos con una clara voluntad de 'mestizaje' (que la población inmigrante participe en la sociedad como ciudadanos que son, y no haciendo gala de su rasgo distintivo), la última área, de Participación y asociacionismo, lo combina con el objetivo, sugerido en el anterior apartado de potenciar la participación como colectivo. El objetivo general es, por lo tanto, 'promover el asociacionismo y las diferentes formas de participación de la población inmigrante, como vía de integración y reconocimiento de los derechos ciudadanos'. Entre los objetivos específicos, encontramos los siguientes:

- Promover y fortalecer el asociacionismo de las personas inmigrantes como forma de participación social

- Fomentar la participación de las personas inmigrantes, sobretodo mujeres, en los espacios donde se produzca una mayor interrelación con la población autóctona: asociaciones de vecinos, AMPA, sindicatos

- Promover el trabajo en red entre la administración local y las entidades de la sociedad civil para augmentar la participación ciudadana de la población inmigrante

- Fomentar la corresponsabilidad de la población inmigrante en la gestión de los servicios municipales mediante su incorporación a todos los órganos de participación existentes: comisiones, consejos, juntas de distrito, etc.

Todos estos objetivos se traducen en la práctica en una serie de medidas que cubren la información i asesoramiento legal, subvenciones, fomento de la participación en 
el entorno (Centros Municipales de Servicios Sociales, asociaciones, etc.), utilización de infraestructuras, fomento de la participación de las asociaciones de inmigrantes en las Mesas de Solidaridad y en las Juntas de Distrito, así como en el futuro Consejo Social de la ciudad.

En resumen, el Plan Norte-Sur también nos facilita una serie de herramientas dirigidas a los inmigrantes, pudiendo enumerar las siguientes:

- Campañas de información y fomento de la participación en plataformas existentes (Juntas Municipales, Mesas de Solidaridad)

- Subvenciones y facilitación de infraestructuras

- Creación de plataformas de participación: Comisión de Inmigración dentro del Consejo Municipal

\section{DE LA TEORÍA A LA PRÁCTICA (EL ANÁLISIS)}

A partir de la lectura de los textos citados hemos identificado dos focos principales: el fomento del asociacionismo migrante, por un lado, y por el otro, las plataformas de participación, ambos con sendos subapartados.

\subsection{El fomento del asociacionismo migrante.}

El asociacionismo de los inmigrantes puede adoptar dos formas: una 'sociabilidad exogrupo' (Lucas Martín et al, 2008; 111), que implica la presencia de las personas migradas en las organizaciones de la sociedad y de la ciudad de acogida, proponiendo la composición mixta entre locales y ciudadanos extranjeros, y una 'sociabilidad intragrupo'; es decir, específica de las asociaciones de inmigrantes. En el primer grupo nos encontramos aquellas medidas que agrupan a los ciudadanos por las cosas que tienen en común, sin importar su origen. Entran en esta categoría las medidas que pretenden reforzar la presencia de los migrantes en AMPA, en asociaciones culturales (como Casals Fallers), en sindicatos, etc. De esto se ocupa el Ayuntamiento principalmente en los apartados de Educación y Interculturalidad.

Con todo, las medidas municipales de fomento del asociacionismo en común son escasas, como en la resta del territorio español, a pesar de que se señale su importancia en la mayoría de Planes (Lucas Martín et al, 2008; 111). En el caso de que se den, suelen orientarse a la población inmigrante en forma de campañas de información, como pasa también en nuestro caso. Esto se combina con otros tipos de medidas, entre las que destacamos:

1. Ayudas concretas y apoyos puntuales para el normal desarrollo de las actividades (como cesión de infraestructuras, etc.)

2. Subvenciones para el desarrollo de actividades y/o proyectos concretos por parte de las asociaciones 
Estas medidas, dirigidas a fortalecer el 'capital puente' (Putnam, 2000) de las asociaciones, ha merecido poca atención, las iniciativas son bastante más escasas. En los dos planes valencianos únicamente se hace referencia al impulso de proyectos en red, pero sin transcender esta afirmación. En la convocatoria de ayudas a proyectos de acción social/lucha contra la pobreza sí que se valora positivamente que se proponga un proyecto en red (base 8.2.b), pero no así en los proyectos presentados en las Mesas de Solidaridad. Por último, también están ausentes las medidas dirigidas a fomentar las federaciones, ya que, como señala un estudio sobre el asociacionismo inmigrante en la Comunitat Valenciana (Falormir Faus, 2014), este está caracterizado por una escasa participación institucional en las plataformas y federaciones de organizaciones existentes.

Remarcamos también que no nos encontramos con medidas para la formación de personal de estas asociaciones, con el objetivo de mejorar su capacitación y conocimiento de los recursos a su alcance (petición de subvenciones, presentación de proyectos, normas administrativas, etc.), pero si apoyo en el proceso de contextualización y adaptación (actuación 3.2.1, Plan de Servicios Sociales) en forma de cursos. Estos van dirigidos, entre otras cosas, al aprendizaje lingüístico, al conocimiento de la cultura de València y de la Comunitat...

Por lo que respecta a las subvenciones, las asociaciones de inmigrantes tienen acceso a diferentes convocatorias de ayudas, para proyectos y actividades puntuales. Algunas de estas son presentadas por los Centros Municipales de Servicios Sociales, concretamente por las Mesas de Solidaridad. Pero de las 70 organizaciones en activo en Valencia solo $7^{24}$ (el $12 \%$ de las entidades) manifestaron formar pare de alguna Mesa de Solidaridad. Yendo un poco más allá, en la convocatoria de ayudas de este organismo para 2014 únicamente 5 asociaciones de inmigrantes presentaron proyectos, de los cuales 2 iban dirigidos a programas de integración.

\subsection{Las plataformas de participación}

\subsubsection{El Consejo Social}

La mayoría de ayuntamientos en el Estado español que se han dotado de un Plan Municipal de Integración y que planean políticas centradas en el colectivo de inmigrantes han creado vías específicas de participación. En particular, han proliferado los consejos consultivos, con la misión de fomentar la participación y abordar cuestiones y retos en los que se ven directamente involucrados. El Ayuntamiento de València, no obstante, pertenece a la minoría que no dispone de estos organismos, y que remite a los mecanismos comunes y generales ya existentes; en este caso, el Consejo de Acción Social. El Plan Norte-Sur preveía, como hemos visto, la creación de una comisión específica, la 'Comisión de Inmigración', que a finales de 2015 aún estaba pendiente de constituirse.

Por otra parte, entre los colectivos que pueden integrar el Consejo no se reserva expresamente ningún sitio a las asociaciones de personas migradas. Solo se puede

$24 \quad$ Falomir Faus, F., 2013, Situación actual y perspectivas del asociacionismo inmigrante en la Comunitat Valenciana, en Informe Anual sobre Migraciones e Integración, CeiMigra. 
entender que tendrían voz de manera indirecta, por pertenecer a una minoría étnica -2 representantes- o a una ONG dedicada a los servicios sociales -también 2 representantes-.

Además, por regla general, la naturaleza de los órganos es de asesoramiento. Nuestra ciudad tampoco marca la diferencia en este aspecto; de hecho, el primer artículo del Consejo Social lo define de la siguiente manera: “(...) órgano de participación social, de asesoramiento y de colaboración en aquellas actividades que incidan en el campo de los Servicios Sociales".

Se trata, por tanto, de un Consejo con carácter meramente informativo y de asesoramiento, en el que existe una representación parcial - los vecinos extranjeros forman una pequeña parte de las organizaciones que la conforman- y indirecta - ya que está basado en el tejido asociativo de la ciudad.

Los consejos arrastran, además, problemas de organización, en València como en otros sitios: escasez de recursos y competencias, falta de oficinas independientes, escasa atención desde áreas de la administración... Es más, a pesar de que la ley que creaba el Consejo Social de la Ciudad era de 2003, este no se constituyó hasta 10 años después ${ }^{25}$.

Por último, aunque no menos importante el reconocimiento parcial del derecho de sufragio ha contribuido a lastrar la legitimidad y apoyo a los consejos sociales (de Lucas, 2008).

\subsubsection{Participación, servicios y políticas de convivencia}

Dentro de esta categoría nos encontramos con medidas que pretenden facilitar la participación normalizada de los nuevos vecinos como usuarios de los servicios y espacios públicos. Este aspecto es relevante, puesto que la inserción en los servicios municipales comporta una notable incidencia ciudadana. Si es positivo, aunque no falten tensiones, compartir instituciones y servicios puede tener efectos inclusivos y facilitar el reconocimiento social de los nuevos vecinos. Por el contrario, si aparecen tensiones relacionadas con el acceso a los recursos, las consecuencias pueden ser terribles, hasta el punto de llegar a una dinámica de la exclusión: se responsabiliza al inmigrante de los problemas $y$, en consecuencia, se le considera un 'vecino indeseable' (de Lucas Martín, 2008; 110).

Las medidas que entran en esta categoría son las referidas a los derechos sociales, como vivienda (punto 4.6.3 del Plan de Inclusión), sanidad (5.1.7), pero también las que facilitan el acceso a la situación de regularidad administrativa (4.6.4), a través de 'servicios de información y orientación jurídica especializados y de la gestión de los informes de arraigo social $^{26,}$.

Otro conjunto de medidas que pretenden favorecer la participación normalizada de los inmigrantes se centran en las relaciones vecinales y en el uso y disfrute de los espacios públicos. En los últimos años asistimos a una creciente importancia de las

\footnotetext{
${ }^{25}$ Vázquez, C. [En línea] Barberá tarda 10 años en constituir el consejo social de la ciudad, 7 novembre de 2013. València: El País Comunitat Valenciana, 7 nov 2013. < ccaa.elpais.com/ccaa/2013/11/07/valencia/1383855930_681184.html> [Consulta: 25 set 2014].

${ }^{26}$ II Plan de Servicios Sociales para la Inclusión Social 2014-2017, Ayuntamiento de València, Concejalía de Bienestar Social y Integración.
} 
políticas de convivencia, conjuntos de medidas que persiguen fomentar el civismo, la prevención de conflictos y la buena convivencia entre vecinos de orígenes diversos, con particular atención a los espacios públicos en tanto que comunes, cotidianos y sensibles. Se trata de una línea más desarrollada y concretada en las grandes urbes, entre las que no se incluye València.

Por último, podemos incluir también en esta categoría las campañas de sensibilización, orientadas al la vecindad, pero también al personal técnico y administrativo (acción 5.1.2), En ocasiones, el personal encargado de los servicios públicos puede servirse de prejuicios en la atención al público. Asimismo, en el ámbito del trato policial, un 36.7\% de las personas encuestadas por un estudio del Ministerio de Sanidad, Servicios Sociales e Igualdad (Suso Araico et al, 2012) indicaban haberse visto afectadas por algún trato discriminatorio por motivos raciales o étnicos. También en la sanidad se manifestaban tratos discriminatorios preocupantes -y eso antes de la reforma sanitaria de 2012-.

De todo lo expuesto anteriormente, se deriva un modelo de participación específico. Siguiendo la esquematización de Font y Gomà (2001) ${ }^{27}$ podemos dividir las experiencias participativas en cuatro categorías: los mecanismos de base asociativa, los mecanismos de deliberación de base personal, los mecanismo de democracia directa y otros mecanismos de democracia participativa.

A Mecanismos de base asociativa: Se incluyen las experiencias que tienen como objetivo el diseño de mecanismos e instrumentos formales de interlocución y diálogo con comunidades sectoriales y territoriales que comparten intereses y/o se ven afectadas por determinadas políticas públicas. Estas son prácticas que enlazan con la teoría del capital social (Putnam, 1995).

A Mecanismos de deliberación de base personal: Se trata de mecanismos que pretenden ofrecer a los ciudadanos información suficiente, el marco adecuado de reflexión y deliberación para que puedan participar activamente en la toma de decisiones. Se trata, principalmente, de crear una igualdad de condiciones en el marco participativo.

A Mecanismos de democracia directa. En este grupo encontramos las experiencias que permiten a todos los ciudadanos entrar de lleno en los procesos de las políticas públicas.

A Otros mecanismos de democracia participativa, como por ejemplo, los presupuestos participativos. También se incluyen aquí las fases finales de las políticas públicas -según los términos utilizados por Subirats (2008)-, es decir, el seguimiento y evaluación de estas, así como el uso de las nuevas tecnologías.

Dentro de estas categorías, las medidas propuestas por los diferentes planes valencianos ponen especial atención a los dos primeros apartados, y mucho menos al tercero y cuarto. Se plantean medidas para información de los derechos y deberes de los inmigrantes, que pretenden suplir la falta de conocimiento al respecto de las diferentes

$27 \quad$ El trabajo de Font y Gomà se centra principalmente en las experiencias puestas en práctica en la Unión Europea. 
opciones existentes. Además, se plantean subvenciones para presentar proyectos, aunque tiene más peso un enfoque culturalista de la integración de las asociaciones. La participación está organizada, sobretodo cuando hablamos de instituciones públicas/políticas, en base asociativa y, podríamos añadir, sectorial, ya que el asociacionismo común tiene poco peso en las medidas, a pesar de fijarse como objetivo, en detrimento de la participación de base personal. La falta de estudios que corroboren su utilidad deberían como mínimo poner en cuarentena su capacidad real de interlocución y como mecanismo de diálogo entre ciudadanos y administraciones locales.

Además, también se puede analizar el contenido de los Planes a través de su 'intensidad participativa'. En este sentido, podemos utilizar la siguiente escala, que mide de menor a mayor- la influencia en las decisiones públicas:

1) Información. Políticas públicas destinadas a dar a conocer las opciones existentes, ya sea en términos más generales o en orientación jurídica (especialmente en el caso de las personas en situación administrativa irregular).

2) Consulta. Plataformas destinadas a conocer la opinión de la ciudadanía, desde una perspectiva global o sectorial.

3) Representación. El modo tradicional de participación, aquí nos referimos a delegar en otras personas para tomar decisiones políticamente relevantes.

4) Cogestión. Plantear proyectos de manera compartida entre la administración local y la comunidad.

5) Autonomía. Proyectos en los cuales la comunidad es la principal responsable.

El foco de atención, ya se ha visto, no va más allá de los dos primeros escalones, ya que la representación no está permitida a todo el mundo.

\section{CONCLUSIONES}

A veces se habla de participación en un sentido estricto, cuando hace referencia a la participación política mediante el derecho a voto y/o la actividad de los partidos políticos. En el contexto de los Planes de integración valencianos, no obstante, se ve claramente que la participación reconoce un rango más amplio -al menos a nivel teórico-, en el que la participación es sinónimo de formar parte de la vida urbana, es decir, no solo involucrarse en asociaciones $\mathrm{y}$ en instituciones políticas, sino ser parte de la vida vecinal en su conjunto, como usuarios de los servicios y espacios públicos y en la totalidad de procesos, relaciones e itinerarios cotidianos.

Reconocer que participar es mucho más que hacer uso del derecho a voto es reconocer que todo es política, y eso nos aleja de una visión rígida donde se miran con recelo la vida y las interacciones vecinales. No obstante, nos encontramos un riesgo institucionalmente cómodo - de altura: sobredimensionar la faceta relacional y cívica para evitar cuestionar el status quo de la ciudadanía. Y es que con lo anteriormente ilustrado intuimos una primera aproximación: que los inmigrantes son tratados más en condición de 'consumidores de derechos' que como ciudadanos y actores. En otras palabras, a la hora de configurar las principales metas de los proyectos nos encontramos con la gran 
retórica de la inclusión participativa, pero dirigida principalmente a garantizar un acceso similar -nunca igual, dadas las restricciones que se plantean en la Constitución y la legislación estatal- a los recursos y servicios, si a caso a los derechos, pero con una importancia menor en su inclusión en los procesos de toma de decisiones. El grueso del contenido de los Planes versa -insistimos- sobre los servicios sociales, sobretodo a partir de campañas de información, de asesoramiento jurídico y muy pocas veces destinadas específicamente a los derechos participativos.

Una política pública participativa debería incluir un abanico amplio de iniciativas, procedimientos e instituciones que fomentan la inclusión de la ciudadanía en el proceso de toma de decisiones colectivas (Conejero Paz, y Segura Cuenca, 2010; 249). Como ya hemos visto, las plataformas de participación que se plantean son variadas, desde el Consejo Social -proyecto embrionario en el que el colectivo tiene, de momento, poca cabida-, hasta la inclusión en AMPA y la participación en Juntas de Distrito a través de las Mesas de Solidaridad. Pero en cuestión de números, se hace evidente que la mayor parte de los esfuerzos se dedican a campañas de información, y que son escasas o incluso inexistentes las acciones que dan más libertad de movimiento a la ciudadanía. Las campañas de información pueden ser un elemento importante para unos vecinos acabados de llegar que se mueven en un entorno ajeno y que por tanto desconocen sus opciones. Pero no puede reducirse a eso, a una mera catalogación de recursos, absolutamente unidireccional y 'top-bottom'. Eso deja poco espacio para la reflexión, para la negociación, y, en definitiva, para la inclusión de los asuntos que interesan al colectivo inmigrante en la agenda política.

A pesar de ser un principio 'constitucional' de los Planes, podemos ver que la participación se entiende mayormente en vistas a los recursos. Y aunque la igualación de derechos y condiciones es sin duda una precondición para poder participar de forma efectiva, es imprescindible ir más allá. En la política pública municipal valenciana los inmigrantes aparecen más como usuarios de servicios que no como actores. Recursos que, además, no son para todos: se reservan para el inmigrante laboral considerado necesario criterio en función de la capacidad de absorción del mercado del país receptor, y por tanto, susceptible a los ciclos económicos-, que se encuentra en situación de regularidad administrativa. Los mecanismos de atención asistencial instrumentados para atender a los 'sin papeles' no son políticas de integración y de asignación de recursos y oportunidades, sino actuaciones humanitarias, dentro de los compromisos relativos a los estándares mínimos de derechos humanes, que, a pesar de eso no siempre se garantizan ${ }^{28}$. La exclusión social tal como ha sido entendida por las autoridades no ha incluido la exclusión política, o si lo ha hecho, de manera muy secundaria, muy por detrás de su significado económicosocial.

Por otra parte, volvemos a dirigir la atención a la forma en la que se vehicula la participación. Al principio hablábamos de que para ser coherentes con la voluntad participativa, el Plan de Servicios Sociales había incluido organizaciones en el proceso de definición del proyecto. Sin entrar en el debate de la incidencia de las propuestas

\footnotetext{
${ }^{28}$ El decreto 16/2012, por ejemplo, que deja fuera los inmigrantes en situación irregular de la cobertura sanitaria, es un claro ejemplo de vulneración de derechos básicos de las personas.
} 
presentadas, nos encontramos con un dato curioso: en el apartado de Inmigración, de las 23 asociaciones consultadas, el 21,7\% (5 de 23) eran asociaciones de inmigrantes, entendidas como grupos formadas por personas de origen extranjero. El resto lo constituyeron asociaciones pro-inmigrantes, es decir, organizaciones no gubernamentales -también sindicatos- defensoras de los derechos de las personas migradas, pero en las que éstas están poco presentes, como nos señalaba el estudio del CeiMigra ${ }^{29}$. Se trata de organizaciones con carácter asistencialista. $Y$ aquí nos encontramos con un problema: hasta cierto punto hay una confusión entre estos dos tipos de asociaciones, que son en esencia muy diferentes en su composición y funciones. A veces, cuando hablamos de la participación del colectivo de extranjeros en realidad se quiere hablar de las agrupaciones que se autoproclaman sus representantes. $Y$, sin negar su papel, es evidente que no es lo mismo.

¿Cuentan las asociaciones con capital social de acceso? Es decir, ¿tienen suficiente incidencia real en el diseño y ejecución de políticas? Y la respuesta, que parece ser negativa, nos transporta a la siguiente, con los mismos conceptos de Putnam: ¿tienen las asociaciones suficiente capital de vínculo?

Llegados a este punto, es vital preguntarse si la base asociativa de la población inmigrante está suficientemente asentada como para resultar representativa. Asistimos a un crecimiento considerable -tanto en calidad como en cantidad- de las reuniones entre ayuntamientos y asociaciones. Eso significa que se dedican recursos, esfuerzos y energías a reforzar la relación con estas entidades, pero esta relación se basa en considerarlos como únicos interlocutores sociales. Se da por hecho que tienen la legitimidad necesaria en otras palabras que son representativos de la sociedad en su conjunto- para tomar decisiones. Y esta es la preocupación principal, ya que su carácter representativo es en muchas ocasiones discutible. En el caso de València, nos encontramos que según un estudio del CeiMigra ${ }^{30}$, de las 167 asociaciones registradas en el municipio, solo se encontraban en activo 70 (diciembre de 2013). Además, se señala el reducido tamaño de estas asociaciones, la composición notablemente etnificada de sus miembros, y una preocupación bastante baja por la reivindicación de los derechos del colectivo ${ }^{31}$.

Hasta aquí nos encontramos con un panorama en el que las asociaciones son poco representativas y el ayuntamiento, a pesar de plantear idealmente el diálogo centrado en ellas, de momento aún las tiene poco en cuenta. Pero, aunque este no fuera el caso y nos encontráramos con un asociacionismo de masas muy implicado en los procesos de decisión, aún deberíamos plantearnos: 'es esa la situación deseada? Algunos autores, como Moya (2010), acusan que la inclusión de las asociaciones en organismos de consulta es una estrategia para aparentar una representatividad otrora sobredimensionada, y en gran medida, falsa, ya que su legitimidad no ha podido ser contrastada por ningún proceso electivo democrático. Al final, según este mismo autor (2010; 498), se exagera la

\footnotetext{
${ }^{29}$ Falomir Faus, F., 2014, Asociacionismo inmigrante y codesarrollo en la ciudad de Valencia, València: Concejalía de Bienestar social e Integración, Ayuntamiento de València y CeiMigra.

${ }^{30}$ Falomir Faus, F., 2014, Asociacionismo inmigrante y codesarrollo en la ciudad de Valencia, València: Concejalía de Bienestar social e Integración, Ayuntamiento de València y CeiMigra.

${ }^{31}$ Solo el $18 \%$ de las asociaciones manifestó realizar actividades específicas de reivindicación de derechos e incidencia política.
} 
importancia real de estos interlocutores para encubrir el déficit de mecanismos auténticos de participación. Otros autores (Veredas, 2003; 207-225, 222) van más allá, entendiendo que las instituciones locales pretenden de esta manera acometer una especie de 'cooptación', dado que es posible controlar los mensajes reivindicativos a partir de las subvenciones. A veces las relaciones se organizan alrededor de entidades o servicios cuyas infraestructuras son relativamente débiles o bien están vinculadas a intereses muy específicos -agrupaciones religiosas, clanes, grupos familiares, etc.- (Moya, 2010).

Es indudable que las asociaciones son instrumentos de creación de opinión y de organización de las comunidades de inmigrantes, y que su papel en la integración y participación pública es fundamental. Es decir, nadie cuestiona su rol en la creación de capital social. El problema radica en basar todo un sistema representativo en ellas. Aún en un supuesto utópico en el que las asociaciones ciudadanas representaran a un volumen importante de la población, repetimos, ¿sería lógico vincular al gobierno local y a la ciudadanía mediante de ellas? ¿No estaríamos sentando las bases para una democracia neocorporativa? En una democracia sana son tan necesarias las políticas de consolidación y mejora del tejido asociativo y de su capital social como de incentivación a la intervención ciudadana en los procesos participativos que se impulsan desde los gobiernos locales.

Si como nos dice A. Mora Cayo, consideramos que integrase equivale a formar parte de la comunidad, no es posible hacerlo desde una situación de inferioridad, desde una realidad en la que existe un acceso desigual a los órganos de participación. O, usando el vocabulario que introducíamos al principio de este texto, que exista una exclusión política. Esta situación iría en contra del objetivo último de la integración. El hecho de que en ocasiones desde los poderes públicos se haya intentado omitir la dimensión política de las personas migradas, reduciéndola a problemas culturales -o 'culturalizándola'- corre el riesgo de etnificar la política. Al substraer a los inmigrantes su integración cívica, se disculpa una situación de profunda desigualdad. Se trata de una cuestión de responsabilidad, pero también de legitimidad democrática, en un entorno en el que esta no sobra precisamente.

La integración se hace de manera parcial, omitiendo su connotación política, puede que por comodidad o por falta de incentivos de cambio político. El caso es que no es la ausencia de políticas sectoriales de inmigración lo que limita las posibilidades de integración cívica, sino las limitaciones legales y de acceso a las instituciones, la falta de incidencia en la vida y las políticas públicas.

El debate entorno a la integración de los extranjeros, podemos concluir, tiende a culturalizar las cuestiones relacionadas con la inmigración, con tal de omitir la reflexión sobre como la inmigración afecta al núcleo de la legitimidad democrática, a la condición de ciudadanía y al vínculo político y cultural de las sociedades receptoras. Al respecto, nos es de mucha utilidad lo que dicen Portes y Vickstrom (2012; 83-108) en Estados Unidos perfectamente extrapolable a un entorno más cercano-: "Mientras algunos académicos y gestores públicos se preocupan por incrementar la participación en las asociaciones locales y hacer que las personas demuestren mayor confianza en otros, se quedan por el camino problemas tan básicos como el diseño de una política migratoria que incorpore de forma efectiva a los recién llegados. En los Estados Unidos, los millones de dólares gastados en investigar si la confianza pública está en declive o si la inmigración la reduce hubieran sido 
más fructíferos de haberse invertido en idear un programa de gestión del trabajo que incorporara de forma flexible a los inmigrantes, y que estableciera vías para promover la integración económica y social para ellos y sus hijos".

\section{PROPUESTAS DE MEJORA: ALGUNAS CONSIDERACIONES}

La democracia se basa, tal como la concebimos hoy en día, en la libertad de todas las personas integrantes de una comunidad de poder elegir de manera libre a sus representantes (Pindádo Sánchez, 2008). No obstante, como opina un sector considerable de la academia, la vertiente representativa de la democracia muestra 'signos de agotamiento' que se manifiesta en un interés bajo en ejercer el derecho a participar en las elecciones periódicas. Varias son las causas que lo explican: falta de credibilidad de los partidos políticos, desconfianza hacia el sistema representativo, falta de transparencia y de rendición de cuentas... La democracia parece estar agotando sus elementos legitimadores. A pesar de ello, no podemos decir que nos encontramos ante su fin. Ya se ha comentado con anterioridad que la elección de representantes no consume? El derecho a la participación; existen otros canales, otras fórmulas con las que ya se ha experimentado en otras partes del mundo -también en España-. Sin embargo, lo que queda claro que la integración de la inmigración no se limita -o mejor dicho, no debe limitarse- al reconocimiento de derechos sociales y laborales, sino que tiene que extenderse al reconocimiento de derechos políticos que garantizan la participación de las personas migradas.

En la introducción citábamos a Subirats en la definición de una política pública como un instrumento que "apunta a la resolución de un problema público reconocido como tal en la agenda de actuación de un gobierno". Delante de una situación que es considerada indeseable, se entiende que si las instituciones actúan haciendo uso de determinadas herramientas (regulaciones, subvenciones, sanciones...), se mejorará la situación, o, en otras palabras, evolucionaremos desde una situación menos deseable a una que lo sea más, aunque no sea perfecta (Bifarello et al, 2013;48). Así pues, cuando a continuación se presentan algunas propuestas de mejora, se trata de avanzar en esa línea, reconociendo asimismo sus limitaciones. Una vez identificadas las carencias y los puntos débiles de la política local de participación dirigida a los inmigrantes, nos proponemos sugerir una serie de puntos que, a base también de experiencias previas en otras localidades, podrían ayudar a una mejor integración de la comunidad, siempre con el objetivo último de conseguir una mejor cohesión social en nuestra ciudad.

"Cuando creíamos que teníamos todas las respuestas, de pronto, nos cambiaron todas las preguntas", nos dice Benedetti. Y es que no debemos olvidar que vivimos en una sociedad en cambio continuo, y que toda política apunta a unos objetivos que constantemente se mueven. Así pues, el que se planeta solo es parte de un proceso, que, una vez permita llegar al punto deseado, la realidad y las mismas exigencias sociales nos empujarán a seguir actuando.

Realizadas las puntualizaciones necesarias, dejamos a continuación nuestra serie de propuestas. 


\section{Potenciar la participación del ciudadano no organizado.}

La identificación grupal es importante, pero sin necesidad de tribalizar la ciudadanía. Es imprescindible dar un papel político a las personas inmigrantes como individuos que también son. Se debería fomentar una cultura más participativa, una educación democrática desde las instituciones, el sistema educativo y los medios de comunicación, pero eso no tendrá sentido si no se garantiza la incidencia política de las personas. No se trata de participar por participar, sino de percibir que la voz propia se escucha: hace falta garantizar procesos que permitan a los ciudadanos formar parte del debate público y de la toma de decisiones. Algunas de las propuestas aplicadas en otros municipios han sido los presupuestos participativos - en Rubí-, o los Jurados Ciudadanos -como en la Escala-. En otros sitios se han utilizado los referéndum -en Palamós, por ejemplo-. Ahora bien, en función de como se enfoque puede resultar difícil de calificarlo como democracia directa (por no ser propuesto a iniciativa de los ciudadanos, por no ser decisorio o por tener que cumplir con condiciones demasiado estrictas).

\section{Transversalidad de la participación}

Por norma general, solo nos acordamos de los inmigrantes en los asuntos que los afectan como colectivo. Debemos dejar de lado esta visión sectorial, tienen que participar en los asuntos públicos en tanto que ciudadanos. El reto de la participación real tiene que superarse necesariamente desde la igualdad, independientemente del lugar de origen, por lo que se deberían potenciar también los proyectos sociales mixtos y que respondan a metas sociales comunes, como se pretendía resaltar en el contexto andaluz ${ }^{32}$ : "cualquier proceso de integración y incorporación de la inmigración al capital social andaluz, y por extensión español y europeo, tiene que enfocarse desde una estrategia de transversalidad, desde una concepción holística de la ciudadanía, sin discriminación ni especialización alguna, evitando la limitación de la participación de las personas en campos específicos, y por tanto, la creación en la práctica de guetos sociales no deseados". Una política será más fuerte y tendrá más posibilidades de ser implementada con éxito cuanto más apoyo e implicación social consiga.

\section{Mejorar el tejido asociativo}

Hemos sido críticos con el asociacionismo inmigrante. Eso no significa, no obstante, que se considere que este no juega un papel importante en la integración de las personas foráneas. Las deficiencias y los retos que hace falta superar son los propios de un asociacionismo joven, aún por vertebrar, y que, por lo tanto, tiene mucha vida por delante. El gobierno local debe potenciar medidas encaminadas a fortalecer el tejido asociativo tanto a través de la financiación, tan necesario en un momento como el actual sin caer en la 'cooptación' de las entidades- como potenciando su inclusión en las fases del

\footnotetext{
${ }^{32}$ S/n. 2013. Participación y diversidad: Avanzando en el papel de la inmigración en la sociedad civil de Andalucía. Andalucía: Libro del proyecto y transcripción de las sesiones, Dirección General de Coordinación de Políticas Migratorias. Consejería de Justicia e Interior. Junta de Andalucía, Coedita: Fundación Civiliter.
} 
ciclo de las políticas públicas, y no únicamente haciéndolas partícipes de órganos consultivos en los que no hay certidumbre de obtener una influencia real. En Roquetas del Mar (Almería), por ejemplo, se ha puesto en marcha el programa 'Nuevas estrategias de participación de la población extranjera residente en Roquetas de Mar, para potenciar un tejido asociativo fuerte que luche para la integración y la justicia social ${ }^{331}$.

\section{Fortalecimiento de la administración local}

En la mayoría de países (del Pino, E., y Colino, 2007;4) la autonomía local está en la práctica limitada por las atribuciones de otros niveles de gobierno y los problemas presupuestarios, cosa que se acentúa en aquellos estados de tradición napoleónica, como el nuestro, en el que la autonomía legal -ya se apuntaba esto al principio- es mucho más limitada. Para avanzar, es inevitable plantear una mayor (y mejor) autonomía financiera, como la que disfrutan los municipios alemanes, y una mejor libertad a la hora de organizarse.

\section{Replantear el modelo binomial de ciudadanía}

Todo el andamiaje jurídico para regular el estatus de los inmigrantes está cimentado sobre el nexo entre el proyecto migratorio y la esfera productiva-laboral (Miravet, 2005). Nuestra Constitución es fruto de un momento histórico concreto, de una España posfranquista, emisora en vez de receptora de inmigrantes, en la que hubiera parecido ciencia ficción plantear una situación en la que la presencia extranjera no fuera coyuntural. A estas alturas, en cambio, requerimos un nuevo planteamiento, no únicamente en aras de la cohesión social, sino con tal de aprovechar el capital social de una parte importante -y permanente- de la sociedad. Sin la modificación de los artículos 23, sobre el derecho de los ciudadanos a participar en los asuntos públicos y de los cargos públicos; y 13.2, que limita a los nacionales españoles estos derechos (con los matices anteriormente planteados), las medidas de participación propuestas no serán más que 'medidas paliativas', mientras sigue sin atacarse el grueso del problema: un tratamiento bien desigual entre ciudadanos que se consideran de primera y otros que 'de facto' lo son de segunda. Es imprescindible abandonar el vínculo entre inmigración y necesidades del mercado de trabajo. Si una décima parte de la población residente en nuestro país es extranjera y tiene vedada la participación en los comicios principales, poca seriedad tiene seguir manteniendo que nuestro sistema democrático tiene una representatividad real y substantiva. España debería seguir la línea marcada por otros países europeos ${ }^{34}$ y permitir el derecho a voto a todos sus ciudadanos.

\footnotetext{
${ }^{33}$ Integralocal. [En línea] Nuevas estrategias de participación de la población extranjera residente en Roquetas de Mar (2011). Almería: Integralocal, 2011

<http://explotacion.mtin.gob.es/integralocal/proyectos_detalleProyecto.action;jsessionid=1080562BC89BD EEBE6B61E87B60AF2B9.vmexpinter54?idProyecto=1078\&tipo=2> [Consulta: 8 sept 2014]

$34 \quad$ Los países en Europa que actualmente han reconocido el derecho al voto de sus ciudadanos de origen extranjeros son Suecia (1975), Dinamarca (1981), Irlanda (1983), Noruega, dos cantones de Suiza, la República Checa, Estonia, Hungria, Lituania, Eslovaquia y Eslovenia.
} 


\section{Dejar espacio para la participación no formalizada}

A pesar de que no entran dentro de los indicadores estandarizados de participación, de no ser 'detectable' para las instituciones, la presencia y agrupación de las personas en los espacios públicos es también un parte importante de la vida participativa. Se trata de interacción, también de visibilidad, especialmente contando con un colectivo en el que todas las personas no tienen porqué estar familiarizadas con vías de participación como la asociativa, pero que no por ello dejan de participar en la sociedad de acogida. La presencia de las personas inmigradas en los espacios públicos es muy alta, lo podemos ver en barrios como Orriols, Tres Forques, la Amistad ${ }^{35}$, "(en la calle, en la plaza, en los comercios, etc.), donde se producen relaciones interpersonales $y$ de intercambio de información, conocimientos o de ayuda mutua' (Salvado et al.,2003; 65-96)' La participación política y cívica no debe limitarse -ni en las personas inmigradas ni en las que no lo son- al ámbito de los derechos políticos directos -sufragio activo o pasivo, principalmente-, sino que tiene que aspirar a un concepto más amplio, en el que se incluya la participación cotidiana en la vida cívica y política.

\section{Hacia un nuevo modelo de gobernanza}

El actual modelo de gobierno es limitado a la hora de enfrentarse a los retos de la nueva ciudadanía. Muchas de las mejoras que se plantean no son posibles desde viejas fórmulas de mandato. Aferrarnos a ellas, aunque cómodo políticamente hablando, es ineficaz cuando se intenta responder al reto de la inclusión.

Uno de los rasgos de esta forma tradicional de gobernar localmente es la monopolización, por parte de las instituciones, de la elaboración de las políticas. Esta dinámica se refuerza en las cuestiones de integración, pero no es un problema que les afecte únicamente. De hecho, al mismo tiempo que señalamos las carencias en los mecanismos participativos destinados a la población extranjera, intuimos muchas de las problemáticas sistémicas: falta de proximidad de la administración, falta de incidencia... Se trata de un modelo que deja poco margen de decisión a la ciudadanía.

Lo cierto es que la participación ciudadana se ha limitado a la elección de los representantes, o bien se ha hecho a través de la autoorganización social (entidades vecinales, grupos de ayuda mutua, sindicatos, organizaciones ecologistas o en defensa de los derechos sociales, etc.). Los espacios formales de deliberación conjunta entre representantes institucionales y sociales han sido tradicionalmente escasos, informales, y con poca incidencia. Se ha tendido a una perspectiva clientelista, cuando lo indicado sería promover una implicación que no se limite al uso de los servicios públicos, o a su evaluación a través de encuestas de satisfacción y cartas de servicios.

Todo esto nos sugiere que tal vez lo que necesitamos es un nuevo modelo de gobernanza. La proximidad de lo local nos permite responder eficientemente a las cada

35 EFE. Más del 20\% de la población en once barrios es inmigrante [en línea]. València: El Levante, 16 de diciembre 2009 <http://www.levante-emv.com/valencia/2009/12/16/20-poblacion-once-barriosinmigrante/661472.html> [Consulta: 1 nov 2014] 
vez más específicas demandas ciudadanas. Ahora más que nunca los gobiernos locales son ágoras en las que responder a nuevos retos. Su posición en primera línea política requiere que sus decisiones también lo estén, para enfrentar nuevos y viejos dilemas sociales. Aún así, sería naif concluir que se trata de una competencia que corresponde únicamente a los niveles locales. Este es un tema transversal, que afecta a los poderes públicos en su conjunto. Instituciones autonómicas y estatales tienen un papel básico a la hora de facilitar una legislación más acorde al momento actual, más considerando que los ayuntamientos están privados de competencias determinantes en materia de inmigración, y en muchos casos tampoco tienen la capacidad normativa suficiente para diseñar mecanismos y programas de los inmigrantes, como sí tienen otros niveles administrativos

Algunos autores han intentado presentar como alternativa "la gobernanza en red". Esta incluye la creación de mecanismos de participación ciudadana, que tienen poca o nula incidencia en los modelos tradicionales de gobierno local. Desde esta lógica, las organizaciones públicas deberían promover la participación de las organizaciones sociales sin olvidarse de la ciudadanía a título individual, no solo en la prestación de servicios, sino en todo el resto de fases de elaboración de políticas públicas: diseño, seguimiento y evaluación de las mismas.

La gobernanza en red no es mas que una propuesta, no exenta de riesgos y problemáticas, delante de un modelo con las horas contadas. Lo que más nos interesa es su preocupación por identificar criterios y estrategias para reforzar la calidad participativa.

La inmigración puede servir como excusa por cambiar un modelo obsoleto. Aún previniendo mecanismos de participación, las instituciones se sirven de un arquetipo unidireccional, es decir, la iniciativa siempre corresponde a la administración. No se trata únicamente de justicia social. Reconocer el papel político de los extranjeros instalados en nuestra ciudad no es solo reconocer un derecho básico de ciudadanía, sino una contribución que enriquece y da nuevas perspectivas y valores a nuestra sociedad civil.

\section{BIBLIOGRAFIA}

Aja, E. 2005. <<La participación política de los inmigrantes $>>$. Puntos de Vista, 2,: participación, Cuadernos del Observatorio de las Migraciones y de la Convivencia Intercultural de la Ciudad de Madrid,

Alba Rico, S. Islamofobia y yihadismo [en línea]. Madrid: Rebelión, 6 de septiembre 2014,, <http://www.rebelion.org/noticia.php?id=189341> [Consulta: 20 dic 2014].

Amengual, A., Astudillo, S, Bosch, M. et al. 2003. Participació i immigració en contextos pluriculturals: la situació al Casc Antic de Barcelona. Escenaris de Participació Ciutadana d'Ecoconcern. Barcelona: Finestra Oberta

Aubarell, G. (dir). 2003. Perspectivas de la inmigración en España: una aproximación desde el territorio. Barcelona: Icaria Editorial, Mediterraneo.

Ayuntamiento de València, Concejalía de Bienestar Social e Integración, Centre de Suport a la Immigració. [En línea] Què és el Centre de Suport a la Immigració (CAI)?. Mayo 2013.

València. <https://www.valencia.es/ayuntamiento/infociudad_accesible.nsf/vDocumentosWe 
bListadov/4510F17AF92705AAC12572C20023E1EC?OpenDocument\&bdOrigen=ayu ntamiento/valenciaya.nsf\&idapoyo=\&nivel=4_1\&lang=2> [Consulta: 12 dic 2014]

Bifarello, M., Subirats, J., et al. 2013. Reflexiones en torno a la implementación de Políticas Públicas Locales que buscan la Cohesión Social. Barcelona: Oficina de Coordinación y Orientación (OCO), Programa URB-AL III.

Bermúdez Torres, A. 2011. <<La integración política de los migrantes latinoamericanos en Andalucía, Madrid y Cataluña >, en García Castaño, F. J. y Kressova, N (Coords.). Actas del I Congreso Internacional sobre Migraciones en Andalucía. Granada: Instituto de Migraciones, pp 1149-1158.

Bourdieu, P. 1986. «<The forms of capital >>, en Richardson, John G., Handbook of theory and research for the sociology of education. Nueva York: Greenwood, pp. 241-258.

Cembrero, I. El Estado Islámico sueña con conquistar Al Andalus [en línea]. Madrid: El Mundo, 04 de septiembre 2014,<http://www.elmundo.es/internacional/2014/09/03/540768e0ca4741406e8b 456b.html> [Consulta: 4 nov 2014].

Conejero Paz, E., y Segura Cuenca, M. 2010. <<Inmigración y democracia participativa >> en Ortega, A. Inmigración, integración, mediación intercultural y participación ciudadana. San Vicente (Alicante): Editorial Club Universitario.

Coussey, M. 2000. Framework of integration policies, Strasbourg: Council of Europe Publishing.

de Lucas Martín, J., Añón Roig, M.J., et al. 2008. Los derechos de participación como elemento de integración de los inmigrantes. Informes 2008, Economía y Sociedad, Bilbao: Rubes Editorial, Fundación BBVA.

del Pino, E., y Colino, C. 2007. Un Fantasma Recorre Europa: renovación democrática mediante iniciativas de promoción de la participación ciudadana en los gobiernos locales (Alemania, Francia, Reino Unido y España). México: UNAM.

EFE. Más del $20 \%$ de la población en once barrios es inmigrante [en línea]. València: El Levante, 16 de diciembre 2009 <http://www.levanteemv.com/valencia/2009/12/16/20-poblacion-once-barriosinmigrante/661472.html> [Consulta: 1 nov 2014]

EUR-Lex, [En línea] Marco común para la integración de nacionales de terceros países. Bruselas: 2010. $<$ http://europa.eu/legislation_summaries/justice_freedom_security/free_movemen t_of_persons_asylum_immigration/l14502_es.htm> [Consulta: 6 jul 2014]

Falomir Faus, F. 2013. <<Situación actual y perspectivas del asociacionismo inmigrante en la Comunitat Valenciana>> en Informe Anual sobre Migraciones e Integración, València: CeiMigra.

Falomir Faus, F. 2014. Asociacionismo inmigrante y codesarrollo en la ciudad de Valencia. València: Concejalía de Bienestar social e Integración, Ayuntamiento de València y CeiMigra.

Font, J., y Blanco, I. 2005. <<¿Qué hay detrás de la oferta de participación? El rol de los factores instrumentales e ideológicos en los mecanismos españoles de participación〉>. Revista del CLAD Reforma y Democracia, 31, Caracas, pp 1-17. 
Font, J., y Blanco, I. 2003. Experiències de participació ciutadana, Polis, La ciutat participativa, Participar en els municipis: qui, com i per què?, Barcelona: Institut d'Edicions de la Diputació de Barcelona

Font, N., 1998. Democràcia i participació ciutadana: algunes experiències innovadores, Barcelona: Editorial Mediterrània, S.L, Fundació Jaume Bofill.

Gadea Montesinos, E. 2007. Las políticas de participación ciudadana: Nuevas formas de relación entre la administración pública y la ciudadanía. El caso de la ciudad de Valencia y su área metropolitana. València: Universitat de València, Servei de Publicacions.

Generalitat Valenciana, [En línea] Sol-licitud d'autorització per a impartir el Programa Voluntari de Comprensió de la Societat Valenciana Escola d'Acollida: Detall de Procediments. València: Generalitat Valenciana. <www.gva.es/va/inicio/procedimientos?id_proc=16202 1/> [Consulta: 25 jun 2014]

González Enríquez, C. 2003. Opinión pública e integración social de los inmigrantes en España, Madrid: Instituto Universitario de Investigación sobre seguridad interior.

Guillot, J. (dir), Salvado A., Díez, L., et. al. 2003. Immigració i poders locals, ciutats i persones. Barcelona: Col·lecció Grana, Institut de Ciències Polítiques i Socials.

Huddleston, T.. Consulting immigrants to improve national policies [en línea]. Brussels: European Economic and Social Committee.

<http://www.eesc.europa.eu/resources/docs/eesc_study_on_consultative_bodies.pdf>. [Consulta: 20 oct 2014].

Integralocal. [En línea] Nuevas estrategias de participación de la población extranjera residente en Roquetas de Mar (2011). Almería: Integralocal, 2011 <http://explotacion.mtin.gob.es/integralocal/proyectos_detalleProyecto.action;jses sionid=1080562BC89BDEEBE6B61E87B60AF2B9.vmexpinter54 idProyecto=1078\&ti po $=2>$ [Consulta: 8 sept 2014]

Jiménez Gálvez, J. [En línea] Las polémicas leyes de extranjería. Madrid: El País, 19 Feb 2014.

<http://politica.elpais.com/politica/2014/02/19/actualidad/1392804222_226752.ht $\mathrm{ml}>$ [Consulta: 20 oct 2014]

Mac Éinrí, P., y Mutwarasibo, F., 2010. <<El reconocimiento del derecho al sufragio de los ciudadanos extracomunitarios en los comicios locales de Irlanda $\gg$, en Sufragio y participación política de los extranjeros extracomunitarios en Europa, 2010, Barcelona: Fundació Carles Pi i Sunyer d'Estudis Autonòmics i Locals.

Maestre, A. El auge de la extrema derecha en Europa, por países. Madrid: La Marea, 25 may. $\quad 2014 \quad<$ http://www.lamarea.com/2014/05/26/resultados-de-la-extremaderecha-en-europa-por-paises/> [Consulta: ]

Coussay, M., y Sem Christensen, E. (Chairman). 1997. Measurement and indicators of integration. Bruselas: Community Relations, Directorate of Social and Economic Affairs, Council of Europe Publishing.

Melero, I., Buades., J., y Díe, L. 2013,. Informe Anual sobre migraciones e integración: Una década de migraciones en España. València: CeiMigra.

Miravet, P. 2005. Trabajadores inmigrantes, sindicatos y participación. Valencia: Cuadernos electrónicos de filosofía del derecho. 
Monsiváis Carrillo, A. 2002. La cosa étnica, La metáfora de la identidad en Harold Isaacs y el análisis del discurso primordialista. Alteridades, vol.12, 24, pp. 119-127, México: Universidad Autónoma Metropolitana Unidad Iztapalapa.

Mora, A. 2011. La participación social y política como instrumento de integración: una aproximación al asociacionismo inmigrante en España y en la Comunidad Valenciana, en Construyendo sociedades multiculturales, Valencia: Editorial Tirant lo Blanc.

Mora, A. 2014. Tema 2: La participación social y política como instrumento de integración, módulo 4, Máster de políticas de integración ciudadana,València: Universitat de València.

Mora, A. 2014. La participación social y política como instrumento de integración, módulo 4, Máster de políticas de integración ciudadana, València: Universitat de València.

Moya, D. 2009. <<Instruments de participació dels immigrants alternatius al sufragi: reptes i alternatives $>>$. CIDOB. Polítiques Públiques i Models de Ciutadania, Barcelona: CIDOB Edicions, col-lecció Monografies.

Moya, D. 2010. <<Regulación del derecho de los extranjeros en España y los mecanismos alternativos de participación política >, en Moya. Sufragio y participación política de los extranjeros extracomunitarios en Europa, Barcelona: Fundació Carles Pi i Sunyer d'Estudis Autonòmics i Locals.

Pastor Seller, E. 2008. La participación ciudadana en los Servicios Sociales Municipales de la Región de Murcia. Murcia: Universidad de Murcia. Departamento de Sociología y Política Social.

Pindado Sánchez, F. 2008. La participación ciudadana en el ámbito local. Andalucía: Federación Andaluza de municipios y provincias, Centro de Estudios Locales y territoriales.

Putnam, R. 2000. Bowling alone: The collapse and revival of American Community". New York: Simon and Schuster Paperback.

Reuters. [En línea] Los primeros sondeos muestran un alarmante auge de la extrema derecha en Europa, Madrid: ABC. 26 may. 2014. <http://www.abc.es/eleccioneseuropeas/20140525/abci-extrema-derecha-europeas-201405252041.html> [Consulta: 30 set 2014].

Salazar Benítez, O. 2006. La Ciudad perpleja: Claves y dilemas del sistema electoral español. València: Ed Laberinto.

Sánchez, E., y Pinyol, G. (coord). 2011. VII Seminario de Inmigración y Europa: Políticas públicas y modelos de ciudadanía, Colección Monografías, Barcelona: CIDOB edicions.

Sierra Fonseca, R. 2001. Integración social y equidad en la perspectiva del desarrollo humano sostenible, 1ạ.ed, Tegucigalpa: PNUD.

Subirats, J. 2008. Análisis y gestión de políticas públicas. Barcelona: Ed. Ariel.

$\mathrm{S} / \mathrm{n}$. 2013. Participación y diversidad: Avanzando en el papel de la inmigración en la sociedad civil de Andalucía. Andalucía: Libro del proyecto y transcripción de las sesiones, Dirección General de Coordinación de Políticas Migratorias. Consejería de Justicia e Interior. Junta de Andalucía, Coedita: Fundación Civiliter. 
Solanes Corella, A. 2008. <<La participación política de las personas inmigrantes: cuestiones para el debate $>$, en Derechos y Libertades, 18, Época II, pp. 67-95.

Suso Araico, A., y González de Chávez, I. 2012. Estudio anual sobre la discriminación por el origen racial o étnico: la percepción de las potenciales víctimas 2011, RED2RED, Madrid: Publicaciones del Ministerio de Sanidad, Servicios Sociales e Igualdad .

Tur Ausina, R. 2013. <<Leyes de participación ciudadana: las experiencias canaria y valenciana >, en Monografías de la Revista Aragonesa de Administración Pública, 14, pp. 203-232.

Vázquez, C. [En línea] Barberá tarda 10 años en constituir el consejo social de la ciudad, 7 novembre de 2013. València: El País Comunitat Valenciana, 7 nov 2013. < ccaa.elpais.com/ccaa/2013/11/07/valencia/1383855930_681184.html> [Consulta: 25 set 2014$]$.

Veredas, S. 2003. <<Las asociaciones de inmigrantes en España, Práctica clientelar y cooptación política>>, en Revista internacional de Sociología (RIS), 36, pp 207-225.

\section{LEGISLACIÓN Y DOCUMENTACIÓN}

II Plan de Servicios Sociales para la Inclusión Social 2014-2017, Ayuntamiento de València, Concejalía de Bienestar Social e Integración.

Declaración 1/1991 del Tribunal Constitucional sobre el alcance y interpretación del artículo $13.2 \mathrm{CE}$.

Ley Orgánica 4/2000, de 11 de enero, sobre derechos y libertades de los extranjeros en España y su integración social.

Plan Norte-Sur 2009-2013, Junio 2008, Sección de Estudios y Planificación, Sección de Participación Social, Ayuntamiento de València, Concejalía de Bienestar Social e Integración.

Recomendaciones del Comité de Ministros del Consejo de Europa, 6 de diciembre de 2001

Registro municipal de entidades ciudadanas. Octubre de 2013.

Registro municipal de entidades ciudadanas. Junio de 2014.

Mesas de Solidaridad 2010- Proyectos Subvencionados, Ayuntamiento de València.

Reglamento del Consejo Municipal de Acción Social del Ayuntamiento de València, 1998, Modificada por acuerdo plenario de: 26.06.2009 y publicada en el BOP: 21.07.2009.

Integración de los inmigrantes en la Unión Europea, Resolución del Parlamento Europeo sobre las estrategias y los medios para la integración de los inmigrantes en la Unión Europea (2006/2056(INI)), Diario Oficial de la Unión Europea, Jueves, 6 de julio de 2006.Font i Llovet, T. 2011. Uniformidad y diferenciación en las instituciones autonómicas y locales en España: Aquiles y la tortuga, en LÓPEZ MENUDO, F. (coord.), Derechos y garantías del ciudadano: estudios en homenaje al profesor Alfonso Pérez Moreno, lustel, Madrid. 